\title{
Motor Learning in Duchenne Muscular Dystrophy, a Literature Review
}

Silvia Regina Pinheiro Malheiros', Denise Cardoso Ribeiro2, Mayra Priscila Bolcolo Alvarez², Bruna Leal de Freitas ${ }^{2}$, Camila Miliani Capelini ${ }^{2}$, Thais Massetti ${ }^{1,2}$, Talita Dias da Silva ${ }^{1,3}$, Rubens Wajnsztejn ${ }^{1}$, Luiz Carlos de Abreu ${ }^{1}$, Carlos Bandeira de Mello Monteiro ${ }^{2}$

\section{Abstract}

Objective: To present and discuss the outcomes in the literature regarding the process of motor learning and/or motor ability in people with Duchenne muscular dystrophy (DMD).

Method: A timeless search was performed in the electronic databases PubMed and BVS (Virtual Health Library), with the keywords "Duchenne muscular dystrophy" (Duchenne Muscular Dystrophy), "motor learning" (learning engine), "motor skills" (ability motor). We used the Boolean AND/OR, and/or to give more specific research and sensitivity to the survey, and papers were only accepted in Portuguese and English. The studies were reviewed independently by two researchers, and after reading the titles and abstracts, they identified the works that were included for analysis and scoring.

Results: The search yielded 18 articles and four studies met all inclusion criteria. The results show that DMD maintains motor learning patterns, even with the progressive dysfunction. They also focus on lower performance compared to individuals with normal development. However, there are differences in the impact and magnitude of the influence of factors such as cognitive ability, deterioration of the perceptual motor process and kinetic impairment in the motor learning of people with DMD.

Conclusion: The process of motor learning in people with DMD remains, even with the progressive nature of the disease, and it is essential to further clarify how this process takes place, as well as the variables behave.
1 Laboratory Design and Scientific Writing. Department of Basic Sciences, ABC Faculty of Medicine, Santo André, SP, Brazil..

2 Post-graduate Program in Rehabilitation Sciences -Faculty of MedicineUniversity of São Paulo, São Paulo, SP, Brazil.

3 Post-graduate Program in Cardiology -Federal University of São PauloPaulista School of Medicine- São Paulo, SP, Brazil.

Contact information:

Silvia Regina Pinheiro Malheiros.

Address: Av. Príncipe de Gales, 821, Príncipe de Gales. Santo André, SP, Brazil

झ s.malheiros@uol.com.br
Keywords
Duchenne Muscular
Dystrophy; Motor Learning; Motor Abilities. Duchenne Muscular Dystrophy; Motor Learning; Motor Abilities. 


\section{Introduction}

Duchenne muscular dystrophy (DMD) is an inherited recessive genetic disease characterized by the absence of dystrophin protein in muscle fiber membrane resulting from mutation of the gene Xp21 $[1,2]$. Its incidence is approximately 1 in 3,500 live birth boys [1].

In this condition, the musculoskeletal system gradually degenerates and weakens with age [3]. The progressive and irreversible weakening of the skeletal, respiratory and cardiac muscles leads to a severe physical disability and shorter life expectancy [4]. Due to the progressive nature of the disease, the person is confined to a wheelchair from about 10 to 13 years old $[5,6]$.

With the evolution of the disease, people become increasingly dependent in relation to activities of daily living ( $A D L)$, and require greater assistance and care [7]. To enable a person with DMD to achieve greater functionality in everyday tasks, the existence of studies investigating therapeutic interventions and their effectiveness in terms of rehabilitation, taking into account the needs and specificities of the disease's progression, is critical.

Currently, there exist several studies on DMD phenotype and genotype $[2,8]$, heart problems [9], postural adjustments [10], physical training [7], multidisciplinary clinical evaluations [11], therapeutic treatments [12], pharmacological treatments [1315], gross motor function and functional disability in terms of mobility, self-care and social function [16]. However, proposals to enable increased functionality through knowledge through motor learning have hardly been explored [17, 18].

Motor learning is a phenomenon that refers to a relatively permanent change in the internal capacity to hold motor skills. These changes occur to ensure achievement of the target and are the fruit of experience and practice, resulting in the acquisition, retention and transfer of motor skills [19]. However, motor learning can be inferred from performance in motor skills, while their improvement can be obser- ved through greater coherence and fluency of movement, decreased runtime error and a reduction in the total movement time to perform a task [20].

Changes in motor development are characterized by deficits in several areas, such as: fine motor, overall balance, body schema and spatial-temporal organization [21]. Speculation about how to effectively organize practice has been made in recent decades in the context of motor learning. As current information on motor learning becomes available, professionals evaluate the principles that form the basis for intervention and replace old and outdated ideas with newer principles.

Given the motor difficulties in muscular dystrophy, it is important to develop researches for clinical and knowledge of DMD about motor learning and this can be done through systematic reviews. Nonetheless, two systematic review studies on DMD [1] claim that the improved cardiac aspect, attention to respiratory function and the judicious use of spinal correction surgery can lead to increased survival among the population, and other study [22] reviewed the breathing treatments needed to increase lung function in Duchenne muscular dystrophy.

Therefore, to support the clinical need and fill the knowledge gap on the subject, the purpose of this study was to analyze research findings about "motor learning and/or motor ability" in people with "Duchenne muscular dystrophy".

\section{Method}

Selecting the articles involved three steps. The first step was looking for articles in databases by reading the titles and abstracts. The second step was excluding works by title or abstract, and our inclusion criteria. The third and final step was analyzing the eligible works. (Figure 1).

The research was carried out using PubMed and BVS (Virtual Health Library). With regard to keywords, we included articles that showed the terms "Muscular Dystrophy," "Duchenne," "motor learning" and "motor abilities." We used the 
Figure 1: 3 Steps.
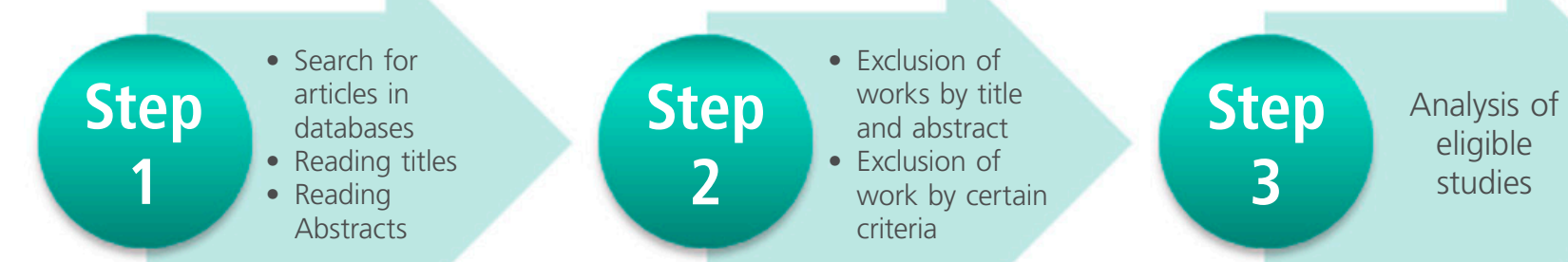

Boolean AND to carry out specific research. In the same way as Snider, Majnemer and Darsaklis (2010) and Massetti et al. (2014) [23, 24], we used a search strategy based on PICOs-P: patient; I: intervention; C: comparison; O: outcomes; S: studys, which is used to locate and compare different studies. (Figure 2).

The following were used as inclusion criteria for the studies: 1. Participants of any age, diagnosed with DMD; 2 . Studies observing the motor learning

Figure 2: PICOs strategy.

\section{PICO}

Population: Duchenne muscular dystrophy

Intervention: various interventions

Comparator (control):

Outcome: results of motor learning and/ or motor abilities

Study design(s): clinical trials, case-control, cross-sectional, case reports and case series. and/or motor abilities of this population. The inclusion of research criteria were: 1. Articles published at any time in the aforementioned databases; 2 . Summaries of the articles are available in English. Articles that could not be located entirely were excluded.

According to the recommendations of $[24,25]$ to increase reliability in the selection of items, all potentially relevant were reviewed independently by two researchers, who, after a full reading, agreed to identify which articles met the inclusion and exclusion criteria.

\section{Results}

The search resulted in 32 articles found in databases; 27 were deleted by title and abstract, leaving five articles for this study (Figure 3) (Table 1) (Table 2).

Figure 3: Extraction process and selection of papers.

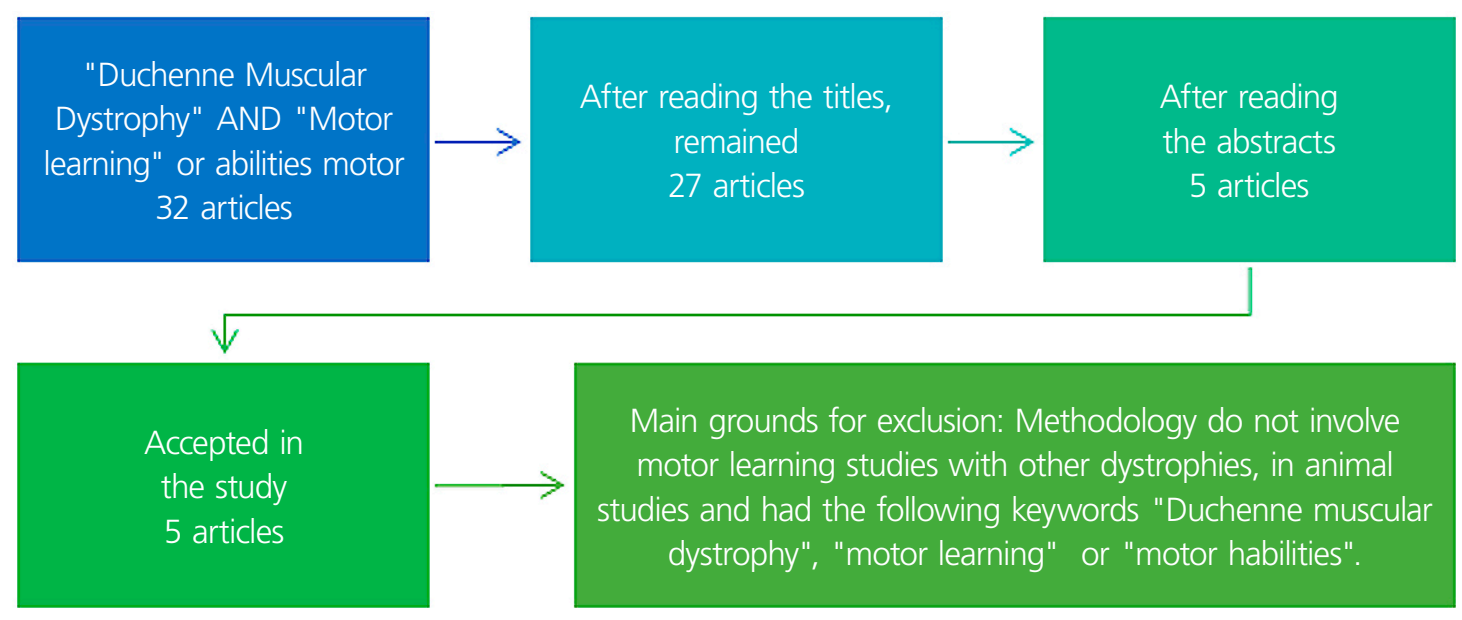


Table 1. Outline methodology of the studies analyzed.

\begin{tabular}{|c|c|c|c|}
\hline Study reference & Nature & Sample & Frequency and duration \\
\hline $\begin{array}{l}\text { Jansen } M \\
\text { et al. } 2010[7]\end{array}$ & $\begin{array}{l}\text { Randomized } \\
\text { controlled trial }\end{array}$ & $\begin{array}{l}30 \text { boys with a DNA-established diagnosis } \\
\text { of DMD will be included. }\end{array}$ & $\begin{array}{l}\text { Six-month physical training during which boys train their legs and arms with active and/ } \\
\text { or assisted cycling training equipment. }\end{array}$ \\
\hline $\begin{array}{l}\text { Parreira SL } \\
\text { et al. } 2007 \text { [26] }\end{array}$ & Clinical trial & $\begin{array}{l}32 \text { patients with Duchenne muscular } \\
\text { dystrophy (DMD), aged between } 5 \text { and } 12 \text {. }\end{array}$ & $\begin{array}{l}\text { Assessments were made monthly for the first six months and with intervals of two } \\
\text { months thereafter until the 14-month endpoint }\end{array}$ \\
\hline $\begin{array}{l}\text { Parreira SL } \\
\text { et al. } 2010 \text { [27] }\end{array}$ & Clinical trial & 90 patients with DMD (aged 5-12 years). & The patients were evaluated in a unique opportunity by using the Hammersmith motor \\
\hline $\begin{array}{l}\text { Nakafuji and Tsuji, } \\
2001[3]\end{array}$ & Clinical trial & $\begin{array}{l}18 \text { patients with DMD and } 28 \text { without } \\
\text { (control subjects). }\end{array}$ & Tests 10 \\
\hline
\end{tabular}

Table 2. Main outcomes.

\section{References}

Jansen $\mathrm{M}$ et al. 2010[7]

Parreira SL et al. 2007 [26]

Parreira SL et al. 2010 [27]

Cincotti et al. 2008 [6]

Nakafuji and Tsuji, 2001 [3]

\section{Main Outcomes}

The primary study outcomes are muscle endurance and functional abilities, assessed with the Six-Minute Bicycle Test and the Motor Function Measure. The primary study outcome is functional abilities of the upper extremity, assessed with the Action Research Arm Test

We conclude that a swift and objective assessment may be performed using the MRC (Medical Research Council) scale for lower limbs and trunk, the Hammersmith motor ability score, timed nine-metre walk and weight lifts.

In patients with DMD aged five to 12 years the progression of the disease is delayed by steroids and motor function is less reduced than muscular strength

The authors report' a pilot study in which a system has been implemented and validated to enable people with disabilities to improve or recover their mobility (directly or through emulation) and communication within the surrounding environment. The system was controlled by voluntary modulation of sensory subjects of EEG rhythms recorded on the scalp; this skill was learned, even if the subjects had no control over their members for a long time.

This study evaluated motor learning and bilateral transfer of learning. DMD patients and healthy people basically have similar learning; however, lower performance in DMD patients was associated with kinetic impairment and not the deterioration of the perceptual motor process. 


\section{Discussion}

Motor learning is defined as the acquisition of movements as a result of practice with retention tests and skill transfer. The effects of the practice can be seen in significant reduction of a task's execution time, besides observing a significant improvement in the quality and organization of movement.

Only one study included in this review seems to be randomized, but it was not explicit. Procedures such as data entry or coin toss should be considered as a form of randomization. Random assignment ensures that treatment and control groups are comparable (within the limits of "random" events) [28]. Beaton et al. (2007) explain that quasi-randomization of procedures such as those based on hospital record number, date of birth, does not satisfy this randomization criterion.

All five studies contained different participants and sample sizes. The largest population was in Parreira et al. (2010) [27] with 90 patients and the smallest population was in Cincotti et al. (2008) [6] with 14 patients. The number of participants is of great importance in order to be able to portray the population that is being studied; however, when we talk about disabled patients, we know that most samples are convenience samples.

With regard to motor learning and Duchenne muscular dystrophy, Nakafuji and Tsuji (2001) [3] "Observed the perceptual motor learning and bilateral transfer a task in people with DMD, compared to individuals with normal development. It was observed performance improvement (learning curve) the dominant hand and quality of bilateral transfer. The results showed that people with DMD presented a perceptual motor learning curve similar to individuals with typical development but with lower performance. The relatively low performance on the task appears to be attributable to kinetic disability rather than the deterioration of the central nervous system process."

Nakafuji and Tsuji (2001) emphasize that perceptual motor learning and its bilateral transfer could be a promising indicator settings mechanism of operation for the external environment and for the control of appropriate motor responses, thereby indicating that the learning process can show flexibility in the coordination of visual and motor areas of the cerebral cortex [3].

According to Van der Weel et al. (1991) [29], motion is not an independent process, but is usually an integral part of one act. The quantity or quality of movement that a person produces will depend not only on peripheral factors such as the limits of muscle activity, but also on their draping ability (depending on practice), interest in pursuing the action and the quality of information available to control movement.

The study by Parreira et al. (2010) confirmed that in terms of motor function, the progression of the disease in the treated patients was slower than that observed along the natural course and also that the Hammersmith scores showed a stabilization across the different ages [27].

Cyrulnik, S. E. et al. (2008) [30] aimed to investigate the adaptive behavior and cognitive skills in children with DMD. Previous studies have documented specific language deficits in older children with DMD, but there are few data on younger children. Therefore 20 children with DMD between 3 and 6 years old and 20 typically developing children were part of the research. The results indicate that children with DMD are classified as backward compared to the control group in adaptive functioning measures. In addition, children with DMD have deficiencies in several cognitive measures, including measures of receptive language, expressive language, visual-spatial skills, fine motor skills, attention and memory skills, and in all areas analyzed, the performance of the children with DMD was worse [30].

The study of Parreira et al. 2007 [26] made use of steroids and described improved MS (muscle strength) and functional abilities, or prolonged ambulation periods. Moreover, they also 
highlighted that in addition to there being effective improvements between the third and sixth months of therapy, this was also followed by a period of stability and deceleration of the loss process, a finding that was replicated in the majority of patients seen.

Due to the many affections caused by disease progression, the quality of life of people affected with DMD is quite low. This leads to a greater dependency in activities of daily living (ADL), and the need for greater assistance and care [31].

In an attempt to unite the knowledge of motor learning with the modernity arising from technological advances, and bearing in mind the benefits that computing can provide in terms of the functionality of individuals with DMD, one of the possibilities for checking motor learning lies in tasks related to interactive computer systems. In this regard, computer systems have proved to be useful since they may enhance the sense of independence of the patient, enabling them to improve communication, home environment management and mobility, in accordance with the residual motor skills of the user.

Among the technologies that can be used as a facilitator of daily activity are brain-computer interfaces (BCls). BCls are systems that can translate the brain activity signals that control external devices. Thus they can represent the only technology for severely paralyzed patients to increase or maintain their communication and control options [6].

The study of Cincotti et al. (2008) [6] was based on a software controller that offers the user a communication interface that is matched with the individual's residual motor abilities in studied patients $(n=14)$ with severe motor disabilities. Due to progressive neurodegenerative disorders trialing a prototype system under a rehabilitation programme was carried out in a house-like furnished space. All users utilized regular assistive control options (e.g. microswitches or head trackers). In addition, four subjects learned to operate the system by means of a noninvasive EEG-based $\mathrm{BCl}$. The authors concluded that such a prototype system, which integrates several different assistive technologies including a $\mathrm{BCl}$ system, can potentially facilitate the translation from preclinical demonstrations to a clinically useful $\mathrm{BCl}$.

The outcomes of the analyzed surveys show by consensus that people with DMD maintain standards of motor learning, even with the progressive dysfunction, but always perform to a lower level than groups of people with typical development. However, the works present different results regarding the impact of cognitive skills in the deterioration of the perceptual motor process in the motor learning of people with DMD.

\section{Conclusion}

Studies evaluating motor learning in DMD are recent, and have sought to understand how the learning process occurs in these patients. In this review, it was shown that despite the functional limitations that accompany DMD to a greater or lesser extent, depending on other variables such as drug intervention, these patients may still learn motor tasks, showing similar patterns to individuals not compromised with the disease, although with lower performance. It was also noted that different instruments can be used in the training of motor skills, from conventional physical therapy to virtual reality therapy, with positive outcomes on motor learning.

\section{Authors' Contributions}

All authors participated in the acquisition of data and revision of the manuscript. All authors determined the design, interpreted the data and drafted the manuscript. All authors read and gave final approval for the version submitted for publication. 


\section{Declaration of Interest}

All authors report no conflict of interest. All authors were responsible for the content and writing of this paper.

\section{Acknowledgments}

Authors would like to thank to CAPES (Higher Education Personnel Training Coordination).

\section{References}

1. K.M. Flanigan, Duchenne and Becker muscular dystrophies, Neurol Clin, 32 (2014) 671-688, viii.

2. H. Foster, L. Popplewell, G. Dickson, Genetic therapeutic approaches for Duchenne muscular dystrophy, Hum Gene Ther, 23 (2012) 676-687.

3. A. Nakafuji, K. Tsuji, Learning and transfer in two perceptualmotor skills in Duchenne muscular dystrophy, Percept Mot Skills, 93 (2001) 339-352.

4. M. Kohler, C.F. Clarenbach, C. Bahler, T. Brack, E.W. Russi, K.E. Bloch, Disability and survival in Duchenne muscular dystrophy, J Neurol Neurosurg Psychiatry, 80 (2009) 320-325.

5. N.M. Santos, M. Rezende, A. Terni, M.C.B. Hayashi, F.M. Fávero, A.A.J. Quadros, L. Reis, M. Adissi, A.L. Langer, S.V. Fontes, Perfil clínico e funcional dos pacientes com distrofia muscular de Duchenne assistidos na Associação Brasileira de Distrofia Muscular (ABDIM), Rev Neurociênc, 14 (2006) 15-22.

6. F. Cincotti, D. Mattia, F. Aloise, S. Bufalari, G. Schalk, G. Oriolo, A. Cherubini, M.G. Marciani, F. Babiloni, Non-invasive braincomputer interface system: towards its application as assistive technology, Brain Res Bull, 75 (2008) 796-803

7. M. Jansen, I.J. de Groot, N. van Alfen, A. Geurts, Physical training in boys with Duchenne Muscular Dystrophy: the protocol of the No Use is Disuse study, BMC Pediatr, 10 (2010) 55.

8. L.R. Peddareddygari, B.H. Pillai, D. Nochlin, L.R. Sharer, R.P. Grewal, Phenotype-genotype analysis of dystrophinopathy caused by duplication mutation in Dystrophin gene in an African patient, Afr Health Sci, 11 (2011) 607-609.

9. L. Bello, P. Melacini, R. Pezzani, A. D'Amico, L. Piva, E. Leonardi, A. Torella, G. Soraru, A. Palmieri, G. Smaniotto, B.F. Gavassini, A. Vianello, V. Nigro, E. Bertini, C. Angelini, S.C. Tosatto, E. Pegoraro, Cardiomyopathy in patients with POMT1-related congenital and limb-girdle muscular dystrophy, Eur J Hum Genet, 20 (2012) 1234-1239.
10. M. Jover, C. Schmitz, E. Bosdure, B. Chabrol, C. Assaiante, Anticipatory postural adjustments in a bimanual load-lifting task in children with Duchenne muscular dystrophy, Neurosci Lett, 403 (2006) 271-275.

11. K. Bushby, E. Connor, Clinical outcome measures for trials in Duchenne muscular dystrophy: report from International Working Group meetings, Clin Investig (Lond), 1 (2011) 12171235.

12. N. Juretic, G. Jorquera, P. Caviedes, E. Jaimovich, N. Riveros, Electrical stimulation induces calcium-dependent up-regulation of neuregulin-1beta in dystrophic skeletal muscle cell lines, Cell Physiol Biochem, 29 (2012) 919-930.

13. V. Malik, L.R. Rodino-Klapac, J.R. Mendell, Emerging drugs for Duchenne muscular dystrophy, Expert Opin Emerg Drugs, 17 (2012) 261-277.

14. V. Raman, D. Yacob, J.D. Tobias, Dexmedetomidine-ketamine sedation during upper gastrointestinal endoscopy and biopsy in a patient with Duchenne muscular dystrophy and egg allergy, Int J Crit IIIn Inj Sci, 2 (2012) 40-43.

15. L. Merlini, M. Gennari, E. Malaspina, I. Cecconi, A. Armaroli, S. Gnudi, B. Talim, A. Ferlini, A. Cicognani, E. Franzoni, Early corticosteroid treatment in 4 Duchenne muscular dystrophy patients: 14-year follow-up, Muscle Nerve, 45 (2012) 796-802.

16. J. Visser, Developmental coordination disorder: a review of research on subtypes and comorbidities, Hum Mov Sci, 22 (2003) 479-493.

17. Y. Hashimoto, J. Ushiba, A. Kimura, M. Liu, Y. Tomita, Change in brain activity through virtual reality-based brain-machine communication in a chronic tetraplegic subject with muscular dystrophy, BMC Neurosci, 11 (2010) 117.

18. R. Leeb, F. Lee, C. Keinrath, R. Scherer, H. Bischof, G. Pfurtscheller, Brain-computer communication: motivation, aim, and impact of exploring a virtual apartment, IEEE Trans Neural Syst Rehabil Eng, 15 (2007) 473-482

19. T. Kitago, J.W. Krakauer, Motor learning principles for neurorehabilitation, Handb Clin Neurol, 110 (2013) 93-103.

20. C.B.d.M. Monteiro, C.M. Jakabi, G.C.d.S. Palma, C. TorrianiPasin, M. Junior, C. de Miranda, Aprendizagem motora em crianças com paralisia cerebral, Revista brasileira de crescimento e desenvolvimento humano, 20 (2010) 250-262.

21. D.C.G.L. Fernani, M.T.A. Prado, R.F. Fell, N.L.d. Reis, T.C. Bofi, E.B. Ribeiro, M.d.T. Blake, C.B.d.M. Monteiro, Motor intervention on children with school learning dificulties, Revista brasileira de crescimento e desenvolvimento humano, 23 (2013) 209-214.

22. C. Martinez Carrasco, M. Cols Roig, A. Salcedo Posadas, O. Sardon Prado, O. Asensio de la Cruz, A. Torrent Vernetta, [Respiratory treatments in neuromuscular disease], An Pediatr (Barc), 81 (2014) 259.e251-259. 
23. L. Snider, A. Majnemer, V. Darsaklis, Virtual reality as a therapeutic modality for children with cerebral palsy, Dev Neurorehabil, 13 (2010) 120-128.

24. T. Massetti, T.D. da Silva, D.C. Ribeiro, S.R.P. Malheiros, A.H.N. Re, F.M. Favero, C.B. de Mello Monteiro, Motor learning through virtual reality in cerebral palsy-a literature review, MedicalExpress, 1 (2014) 302-306.

25. R.F. Sampaio, M.C. Mancini, Estudos de revisão sistemática: um guia para síntese criteriosa da evidência científica, Braz. J. Phys. Ther.(Impr.), 11 (2007) 83-89.

26. S.L. Parreira, M.B. Resende, M. Della Corte Peduto, S.K. Marie, M.S. Carvalho, U.C. Reed, Quantification of muscle strength and motor ability in patients with Duchenne muscular dystrophy on steroid therapy, Arq Neuropsiquiatr, 65 (2007) 245-250.

27. S.L. Parreira, M.B. Resende, E. Zanoteli, M.S. Carvalho, S.K. Marie, U.C. Reed, Comparison of motor strength and function in patients with Duchenne muscular dystrophy with or without steroid therapy, Arq Neuropsiquiatr, 68 (2010) 683-688.

28. D. Beaton, C. Bombardier, F. Guillemin, M.B. Ferraz, Recommendations for the cross-cultural adaptation of the DASH \& QuickDASH outcome measures, Institute for Work \& Health, 1 (2007) 1-45.

29. F.R. van der Weel, A.L. van der Meer, D.N. Lee, Effect of task on movement control in cerebral palsy: implications for assessment and therapy, Dev Med Child Neurol, 33 (1991) 419-426.

30. S.E. Cyrulnik, R.J. Fee, A. Batchelder, J. Kiefel, E. Goldstein, V.J. Hinton, Cognitive and adaptive deficits in young children with Duchenne muscular dystrophy (DMD), J Int Neuropsychol Soc, 14 (2008) 853-861.

31. K. Uchikawa, M. Liu, K. Hanayama, T. Tsuji, T. Fujiwara, N. Chino, Functional status and muscle strength in people with Duchenne muscular dystrophy living in the community, J Rehabil Med, 36 (2004) 124-129.

\section{Comment on this article:}

\section{(f) $[$ in $8+\boldsymbol{S} P$}

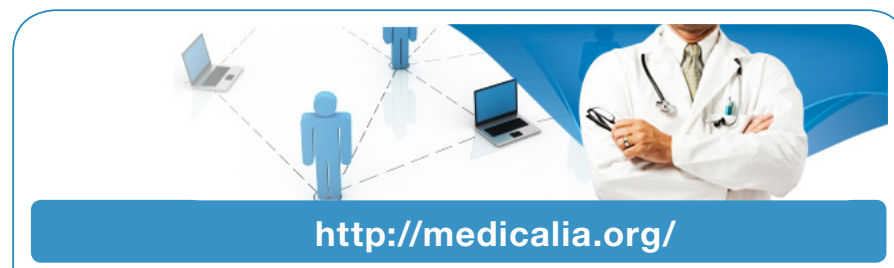

Where Doctors exchange clinical experiences, review their cases and share clinical knowledge. You can also access lots of medical publications for free. Join Now!

\section{Publish with iMedPub}

http://www.imed.pub

International Archives of Medicine is an open access journal publishing articles encompassing all aspects of medical science and clinical practice. IAM is considered a megajournal with independent sections on all areas of medicine. IAM is a really international journal with authors and board members from all around the world. The journal is widely indexed and classified Q1 in category Medicine. 